\title{
SALES EXPERIMENT OF A NEWSPAPER PUBLISHER: "PAY WHAT YOU WANT"
}

\author{
Lukas Bernfried Bruns ${ }^{1}$
}

\begin{abstract}
Digitalization poses great challenges for companies and especially for newspaper publishers. Due to the large number of digital competitors on the advertising market, media companies are forced to proactively win customers. A major German media company has thus dared to experiment and put the question of pricing for booking newspaper advertising in the hands of its customers. With the so-called "pay what you want" (PWYW) payment model, customers can be won and additional budgets spent. This paper explores the question of whether PWYW is a suitable sales model for newspaper companies and which factors have an influence. The results of the interviews with those involved show solutions, opportunities, problems and that additional turnover can be generated.
\end{abstract}

JEL Classification Numbers: M31, M37, D40, DOI: https://doi.org/10.12955/peb.v2.249

Keywords: sales, marketing, payment model, negotiations, customer involvement.

\section{Introduction and Literature review}

With its primary products, the newspaper and the advertising journal (weekly newspaper), the German newspaper industry has been experiencing declining revenues and circulation for more than a decade, and the critical situation in the industry is not expected to improve in the next few years either - it may even worsen (Mündges \& Lobigs, 2020). Digitalization is forcing publishers to transform digitally, and yet the weekly and daily newspaper business model is in danger because a reduction in readership and explicitly declining revenues in the advertising market are the rule and not the exception (Daum \& Hoppe, 2020). Classic print advertising is no longer a self-perpetuator (Dorner, 2016) and therefore requires a proactive approach to generate revenue in sales and to win or retain customers who have become critical. Advertisers, today, have the ability to distribute their desired messages through countless channels and media. Furthermore, digital technology enables the sought-after recipient to search for or compile his or her own desired media and content, increasingly bypassing traditional media offerings (Zurstiege, 2020). Publishers are in a phase of "trial and error," driven by the danger and changes of digitalization, and in the process, amongst other things, no pattern for solution models has been found throughout Europe (Hummel, 2020).

A newspaper company therefore has to come up with a lot to convince advertising customers of its product portfolio, because a print product has no other advantages that can compete with digital advertising apart from ad size, placement and circulation. The Internet has basically become an all-inone medium (Kochhan, Elsässer \& Hachenberg, 2020).

A major media company took a special approach to activating customers. The sales staff were allowed and expected to offer their customers advertising space in the weekly newspapers ( $>500,000$ circulation, $>100$ sales staff) and the customer was to decide for himself in which size, in which circulation and above all at which price he would pay. This pricing model is known as "pay what you want" (PWYW). PWYW is a pricing and distribution model in which the purchase price for a product or service is determined solely by the buyer. Products or services are therefore offered without a set price, and the buyer decides what price he wants to pay. The seller bears the risk for this. The exchange of services for money takes place exactly at the price stated by the buyer, without the seller being able to withdraw from his offer.

In the model that has been increasingly popular or studied in academic papers since the beginning of the 21st century (Narwal \& Nayak, 2019), the PWYW offering is primarily found in the entertainment and culture industry, restaurants and cafes, hotel and travel services, sports and leisure, or simple digital services (Chung, 2017). This circumstance makes the offering of PWYW by a media company quite a novelty. One rationale is that PWYW is more often used as a sales tool when a company competes with other companies in its market, and PWYW is more likely to occur in markets with some degree of product differentiation (Samahita, 2019). The media company under study cannot demonstrate significant product differentiation and a competitive (print) market. It should also be emphasized that customers were targeted "business to business", because customers should buy advertising for themselves or their companies. Since the customer is usually not disadvantaged by well-prepared print

\footnotetext{
${ }^{1}$ Comenius University in Bratislava, Faculty of Management, lukas.bruns@fm.uniba.
} 
advertising (Dorner, 2016), the investigation carried out of this pricing model campaign is unusual, because theoretically every customer would have to take advantage of the service, because their company receives advertising and thus possibly in turn sales and profits, even if they only pay a very small or symbolic amount in the end. A media company thus theoretically has the opportunity to gain satisfied customers and obtain print sales for itself through PWYW. Whether PWYW is a suitable sales model for newspaper companies acts as a research question to be answered here. The aim is to gain a better understanding of the PWYW pricing model, to identify the relevant and influencing success and failure factors, to weigh up the opportunities and risks and to compare and process the views of the publishing house employees involved.

Although the customer determines the price in a PWYW offer and could strongly exploit the situation to his advantage, studies (Egbert et al., 2015; Kunter, 2015; Samahita, 2019) show that the price is usually significantly different from zero and that good prices can also be obtained for the seller (Hoffmann, 2016). Moreover, study results suggest that higher sales through PWYW can compensate for the resulting lower prices (Roy, Rabbanee \& Sharma, 2016).

\section{Method}

In order to answer the research question ("Is PWYW a suitable sales model for newspaper companies?"), six (expert) interviews (random sample) were conducted with a selection of relevant people from the company, consisting of management (CEO), publishing managers, and key account managers. Through these individuals, it is possible to draw directly and indirectly on the results and experiences as well as implementation of approximately 50 sales staff. In addition, the respondents themselves were active with the PWYW offering. Methodically, a structured questionnaire was developed in order to inquire about situation interpretations, motives for action, results, reactions and behaviors in as unbiased a manner as possible. The aim of the study is to methodically and systematically obtain excerpts of reality through the statements and findings of the qualitative survey technique of "interview". In addition, the six semi-structured interviews are intended to capture personal perspectives, motives and individual opinions. The interviews were conducted and recorded individually and in the context of a video conference. Subsequently, all interviews were transcribed and accentuations as well as content-related particularities were marked.

The 18-question questionnaire was designed to allow respondents to answer the questions openly, narratively, and freely. The questionnaire thus served as a guide to cover all important topics and to ensure comparability of answers without having to forego individual interview requirements or process changes. The respondents were informed in advance about the aim and subject of the study. They were also assured anonymity and interviews were conducted in the evening in a private setting to minimize potential stressors for participants. All participants took part voluntarily and had the right to withdraw. The aim was to "understand" opinions, views, actions and motives as well as contexts on an ongoing basis.

The choice of the interview method is suitable when scientific findings are to be reconstructed and a high degree of openness is to be ensured for this purpose (Niebert \& Gropengießer, 2013). The interview partners were not given any time constraints and were also asked to tell as much as possible about the individual questions. If necessary, there were spontaneous interventions to deepen relevant facts or to clarify ambiguities. In addition, the briefly formulated and specific questions of the questionnaire, which only referred to the aspect of PWYW, had a planned structure (order of the questions).

The order of the questions was: a. regarding the time before the application of the pricing model (situation, concerns, goals, preparation), b. clarification of actors and actions (people, approaches, avoidances, and courses of action), c. changes and tactics, d. experiences and insights (customer reactions, experiences, conversations, closures, rejections, customer retention, utilization, and sales) and final evaluations and afterthoughts (sustainability, evaluation of PWYW, and other comments). In addition, the questionnaire was tested in a small pre-test with two subjects to determine comprehension of the questions, effects of the order of the questions, context effects and e.g., duration.

Finally, the questionnaire was structured in a way that the questions refer to the same aspects as far as possible. Ultimately, starting from a preliminary understanding of the topic, a circular approach was taken to the selection of the method, then the selection of the units of inquiry, the collection of the data, and finally the data analysis (Witt, 2001). In the analysis itself, specific codes were classically assigned 
to the individual text fragments, sentences, or paragraphs (open coded, inductive), which were selfgenerated or adopted from the knowledge of the existing literature. The resulting condensed statements could then be understood as a system of categories, by comparing and connecting the individual codes into a superordinate category. In the inductive procedure, the categories were determined in an interrelation between the research question and the individual statements according to assignment rules and constantly revised, reviewed and interpreted in relation to the initial question. Finally, eight categories were interpreted.

\section{Results}

The research questions posed are intended to be answered by the findings from the categories that have been classified as a relevant influencing factor for the research. Additionally, these findings were compared and enriched with the findings of the current PWYW literature.

\section{Reasons}

The analysis of the interviews here very clearly reveals the reasons why staff chose PWYW. Uniformly, participants were concerned with generating additional revenue that was not planned for on an annual basis, or receiving additional budget from customers ("I thought it was a fun approach, just thinking, is it a way to increase revenue during this time, "Yes, definitely getting additional sales"). A smaller aspect is to find out the perception of the subjective estimation of the customers concerning the own offers and prices ("The consideration was quite simply to check once whether customers know what our service is worth"). The results are consistent with the current state of research, among other things, in that the campaign took place in August, a time of low sales for the product offered ("silly season") and is often used by companies precisely then: "Some firms use so-called customer-driven pricing mechanisms to sell excess capacity in times of low demand"(Krämer et al., 2017). Ultimately, companies in sectors or industries want to use PWYW to generate revenue (Weisstein et al., 2019), as was the case in the media company in question.

\section{Advance}

With respect to the "upfront" category, it is notable that the general preparation of the vendors was reportedly very brief and not very detailed. E.g., in no case was there any mention, even in response to follow-up questions, of how the salespeople had dealt with the PWYW issue and its specifics in advance. There were team discussions and the coordination of customer potentials as well as segmentations of customers ("Yes, customers selected, potentials defined", "...well, I only told that to good customers", "The ones we just knew were so price-critical") as well as the intention to show a special concession with the offer to particularly "good" or particularly price-critical customers, but there was little evidence of preparations in the matter (arguments, sales techniques, understanding of the price model, etc.).

Why prior knowledge matters in sales and PWYW, studies suggest, is because a so-called reference price when accepting and paying for a PWYW offer is important (Gerpott, 2016), especially if a customer has a reference to the actual price of the offer and they can mentally recall that reference (know the price or have already paid a price for a (similar) product). Furthermore, it is important whether the consumer also considers these reference prices to be credible or reasonable (Gerpott, 2016). Moreover, Kukla-Gryz and Zagorska (2017) found that PWYW values increase with an external reference price, even if the expected quality of the offered product is unchanged. Moreover, it was found that when the internal reference price a customer has is higher than the external reference price, PWYW payments are significantly higher than when no reference price is given at all (Kukla-Gryz \& Zagorska (2017).

In addition, the anchor effect should be mentioned here. In reference to Gläßner (2017), the anchor effect means that people are strongly influenced by initial values. Thus, the anchor effect shows that a high value acts in advance to be highly valued again later and can influence the purchase decision especially in a PWYW situation. Additionally, the following should be noted: Stürmer and Schmidt (2014) argue that price often acts as an indicator of the value of an offer. Consequently, potential customers might have problems evaluating the offered product or service quality if they do not know a fixed price. It is thus actually indispensable and to be classified negatively, if salesmen do not know and in consequence also not consciously use these systematics.

In the end, the evaluation of the interviews also did not reveal any uniform procedures, specific avoidance or action patterns. It is clear that the customers were predominantly referred to the offer impersonally by an e-mail ("...then we wrote to them, and a day or two afterwards we phoned them, 
some of them also got in touch directly then.", "I was very annoyed that most of them only contacted their customers by e-mail."). Changes or sales adjustments during the sales process, as well as tactics or strategies, cannot be read or interpreted from the data.

\section{Social reference}

The relationship of sellers to their customers seems to have a high influence on the successful implementation of PWYW. The evaluation proves that the relationship between seller and buyer is important and shows a positive picture with regard to the acceptance of the offer and the payment of good prices ("And there is a reciprocal effect, I think he can estimate very well what will happen if he really charges outrageous prices. Eh, that won't necessarily have a positive effect on the future business relationship, you'll be more careful with discounts in the future or the business relationship will be a bit prejudiced, because you always know that he took advantage of that. I believe that sensible business people simply don't take that risk.", "...I simply noticed that the work from the past, i.e. the relationship, simply bears fruit in the action."). Additionally, long business relations and the intention of the continuance of the relations seem to play a role ("...these are simply long-standing clients and they also pay well", "...but that was also up to us as advisors to work with the clients accordingly.... These were people who were very critical of us, but who were already long-standing customers."). Beyond that, it is noted that customers with whom there is a difficult business relationship pay poor or even very poor prices even when accepting the PWYW offer ("...then we noticed that, due to the different customer characters, there are of course also the total outliers, who paid one euro for half a page of advertising...", "...is also always a very loyal and honest business partner and the other customer tends to be the one who always tries to get an advantage somewhere", "Partly our customer relationships, contacts, also from the past, were simply too bad, they then flattened us.").

These findings are also reflected in PWYW's research literature. The literature states that personal contact between the buyer and seller can influence a willingness to pay. Positive payments are mainly influenced by social preferences such as an aversion to unfairness and by the buyer's strategic motive to support the seller in further participation in trade and market activities (Schmidt, Spann \& Zeithammer (2015). Marett et al. (2012) consider social factors important and mention loyalty and fairness, which should be strong in the customer base to achieve good results and prices with the PWYW approach. Kim, Kaufmann and Stegemann (2013) also confirm this: "Social distance within the buyer-seller relationship also affects PWYW prices."

Customer Reaction

The category "customer reaction" shows divergent results. On the one hand, customers react "astonished" about the offer and the offer is declared with "negative reference" or as a "desperate act" ("...But now you need it", "...is this the last revolt now? ", "Yes, they thought it was a joke", "...well, they really meant whether I was pulling their leg, partly because then I really said you can choose...", "they just didn't believe me at the beginning.") as well as mistrust towards the action becomes clear. Nevertheless, acceptance, joy and curiosity are also visible ("Because they are already used to very high prices from us and then to choose what you can pay, that's a cool feeling", "...some customers were totally curious", "A few didn't react at all, they were immediately in negotiation mode", "...and you mustn't forget that every customer who confronts us is also a salesperson somewhere"). Ultimately, the price model can be a good conversation starter in negotiations ("...and about the offer and then a conversation just resulted from that.").

At this point, it should be emphasized that there is evidence (Menthe \& Sieg, 2018; Carlsona \& Weathers, 2008; Pütter, 2019) that the trustworthiness of the seller, preconceived opinions and expectations of the customer and the reputation of the supplier, as well as previous experience, are important factors when offering purchase promotions and thus price models (both - positive and negative).

Results

The first and most important item to be described is that the PWYW price model campaign definitely led to additional sales for the media house and brought in additional budgets or ancillary sales (also in line with the targets) ("Additional sales: yes, yes, I can sign off on that.", "...more sales than we would normally have achieved via 'a normal list price campaign.", "Because that's simply the sales that the customer probably wouldn't spend like that.", "...I would never have seen the money otherwise."). 
Furthermore, a majority of customers accepted the offer ("...I would now say, of the customers where I offered it, 60\% have accepted the offer.", "that the majority have then accepted the offer", ...Honestly, of my customers, actually everyone has bought."). Fluctuations in the prices could be determined, but nevertheless according to statements of the interviewees good and also high prices were obtained ("...that these fears were actually far-fetched and that this avarice fortunately did not come true.", "...the prices were indeed more favorable than tariff, but by far not so far under, as we had feared at first", "...and it was already so that the price estimate of the customers quite realistically took place.", "I was able to achieve really high prices in some cases, but not always", "...they set the prices relatively high. So, no one dared to say "one euro"."). The prices were often within a price range that the sellers and the company could manage well and were satisfied with. Nevertheless, there were also critical voices and exceptions ("Well, that, eh, the range was incredibly wide." ,"There were also outliers.", "Some people have already come to me and asked: "Can I really do that?"). One manager was even more critical: "...hm, I wouldn't do it again.", "If I now compare the time spent and the turnover, then perhaps it was still a deal in which we earned money."

Previous research suggests that the PWYW method can lead to high customer acceptance, although the so-called price discrimination aims to sell the same good at different prices (Kalka \& Krämer, 2020). This approach suggests that higher sales and profits can be achieved than, for example, with uniform price bids (Kalka \& Krämer, 2020).

Certainly, not every customer is willing or able to name a price. For one thing, some customers are not capable of thinking about a price, and for another, customers may be afraid of paying too much, too little, or a socially inappropriate price. In addition, PWYW may be perceived by customers as too innovative or may make them feel insecure because they are simply unaware of such promotions or they are not common (Sander, 2019). There are social norms in buying and selling that customers are aware of or prefer. People may find it difficult to break out of these social norms and they feel bad, ashamed, or guilty when they break the norm (Rienera \& Traxler, 2012). It should also be noted that customers have difficulty determining the provider's existing costs (which they need for a reasonable price) and therefore provide lower estimates (Schons et al., 2014). To prevent this effect, practitioners implementing PWYW should communicate cost information at first contact to adjust clients' initial estimates. Finally, there is data showing that pricing strategies based on the customer's estimated use value are more useful in undermining price discrimination, increasing sales, and being more competitive than when production costs are known to the customer as a baseline value (Antoun-Nakhle et al., 2020). Ultimately, and critically, a quote from Raju and Zhang (2010) should be included: "Set pricing makes every transaction an adversarial encounter, a conflict in which neither the seller nor the buyer ever leaves completely satisfied."

\section{Findings}

As a finding from the sales work with the PWYW pricing model, it can generally be determined that PWYW is a good tool for winning old or new customers or for refreshing partnerships ("... have the feeling ... customers will work more closely together in the future, there is still room for improvement, or you are running out of arguments, .., conjures this marketing action from the hat, ..., tries to convince him of... with your services and see if you can keep the customer this way, ... or generally win him over to the topic of advertising for once..."). Nevertheless, it is also admonished and recommended to use the product little or sparingly ("Pay what you want is a poison that is only good in small doses and after use should be quickly put back in the poison cabinet.", "...I liked it, I would recommend it, but only on the background that you just think carefully to whom you offer it.", "I think the customer should not get used to it or know when we plan such actions.").

Hofmann (2016) describes that PWYW allows old customers who have switched to other offers (sellers/companies) or show less interest to buy again or re-establish a business relationship. Additionally, it remains to be noted that in general, and regardless of whether they are new or old customers, there appears to be a tendency for buyers to behave "fairly" with PWYW (Haws \& Bearden, 2006). This fact argues against the proposition that PWYW is a "poison" or should only be offered to certain customers and with time limits. Nevertheless, there are also research findings that suggest that PWYW price promotions both generate less willingness to pay or buy with steady or increased use - but also the opposite can be observed, or the factors per se do not play a role at all. (Greiff \& Egbert, 2018; Antoun-Nakhle et al., 2020; Birnberg et al., 2020). 


\section{Sustainability}

There are indications that working with PWYW pricing models can deepen or stimulate new business relationships, and that sustainable sales are also achieved, but the data or interview statements confirm this only moderately ("with one or the other customer it was or is sustainable sales, yes, for sure", "'... so clearly, we were afterwards already better in contact with some customers, but how much is also difficult", "medium-term effect was already there", "that one got more out of the market and that the people were pleased also somewhere, if one called", "not the price-sensitive"). It is also interpreted that these data of "sustainability" were not systematically recorded in the company and the employees did not think much about the point. That is why no reliable statement can be made here. One employee even answered in the opposite way and could not confirm sustainability in terms of sales ("No, no, you can't read that from it.").

\section{Instrument}

The answers to the category "instrument" are weak. With one exception, the experts or interviewees defined PWYW as a good sales model, but probably related the statements primarily to the generation of sales, neglecting all other factors around the pricing model. Furthermore, the statements show little "enthusiasm" in the sense of a positive evaluation of the PWYW action ("And therefore I would say, clearly, in certain situations or at certain times one can make such a thing already again and again",

"...and the advisors and the salesmen also the chance gives to step again more with the customers into contact, where one can exclude in advance something, i.e. the stupid price discussion. ", "I judge it, so I judged it, no, I judge it well", Thus, I would say, it is 'a better marketing measure", "if I see it as a customer relationship tool, it is completely good", "clearly that is good, I suggested also to drive the action more frequently or in special situations").

From a customer perspective, the work of Maziriri and Madinga (2015) should also be acknowledged, as they describe that buyer remorse has an influence on future purchases from a seller. Thus, it is important that PWYW also leads to satisfied customers (and not just satisfied sellers) if a business relationship is to be successful in the future. Furthermore, it can be concluded from the literature that interactivity ("customer determines the price") and related pricing mechanisms, as well as consumer involvement, can generate a higher level of attention and are also suitable for sales promotion activities, allowing companies to differentiate themselves from other sales promotion activities, or to generate interest while making pricing entertaining and exciting for the buyer (Hinz \& Creusen, 2009).

Returning to the question of whether PWYW can generate additional revenues for a media company, the evaluations of the interviews show a positive picture. General conclusions can be drawn about other media houses (or providers of advertising space) and are additionally supported by the results of the current PWYW literature. The results and statements can be clearly interpreted and there is sufficient oral evidence. Nevertheless, critical features are also noted (e.g., too much work in relation to the result), but these do not sufficiently refute an overall affirmative result. However, the number of interviews is too small to speak for an entire industry and similar companies from different regions and to draw conclusions about other sales areas. Nevertheless, this experiment of a newspaper house shows possibilities, dangers and potential for improvement in the implementation of a PWYW method. Nonetheless, according to our own personal assessment, the PWYW model is obviously not enough to provide a real counterweight and long-term solution to digitalization. Our own subjective interpretation of the statements from the interviews must be viewed critically. Other researchers could possibly evaluate the results differently. Another point of criticism is the not pronounced use of theory building methods. Due to the partly short interviews, not many codes were written down and developed and, in the end, only few relevant categories resulted for the analysis, which were then evaluated and analyzed. Nevertheless, this significantly reduced the overall complexity needed to get to the core of PWYW.

\section{Conclusion}

The research question "Is PWYW a suitable sales model for newspaper companies?" can be positively evaluated on the basis of revenue generation (especially in a period of low sales). It is possible through PWYW to obtain additional revenue from customers in the existing market and also to realize economically justifiable and good prices. Nevertheless, a publisher also bears risks in doing so, because not every customer is capable of dealing with such an offer or behaving "fairly". This can result in rejection and poor or low price offers. It seems to be important for a newspaper company that the sales 
people deal with the theory of the price model in order to show better results in the market. Additionally, good and established business relationships with customers are important. In sales, the pricing model is useful in addition to revenue generation to maintain, reactivate or expand business relationships. Ultimately, however, experts caution against too frequent and general use. This warning cannot be sufficiently substantiated from the current research literature.

\section{References}

Antoun-Nakhle R., Hariri N., Haidar R. (2020) Pricing Digital Arts and Culture Through PWYW Strategies. In: Bach Tobji M.A., Jallouli R., Samet A., Touzani M., Strat V.A., Pocatilu P. (eds) Digital Economy. Emerging Technologies and Business Innovation. ICDEc 2020. Lecture Notes in Business Information Processing, 395, 166-176. doi: 10.1007/978-3030-64642-4_14

Birnberg, J. G., Choi, J., Presslee, A. (2020). Giving Customers Decision Rights: A Field Study of Pay-What-You-Want Pricing at a Performing Arts Theatre. doi: 10.2139/ssrn.3662817

Carlson, J.P, Weathers, D. (2008). Examining differences in consumer reactions to partitioned prices with a variable number of price components. Journal of Business Research, 61, 724-731.

Chung, J. Y. (2017). Price fairness and PWYW (pay what you want): a behavioral economics perspective. Journal of Revenue and Pricing Management, 16(1), 40-55. doi:10.1057/s41272-017-0078-0

Daum, M., Hoppe, M (2020). Branchenanalyse Zeitungsverlage. Working Paper Forschungsförderung, 177, Hans-BöcklerStiftung, 10-21.

Dorner F. (2016). Wirkung von Advertorials und klassischer Printwerbung. In: Advertorials versus klassische Printwerbung. Handel und Internationales Marketing Retailing and International Marketing. Springer Gabler, 112-122.

Dorner, F. (2016). Advertorials versus klassische Printwerbung: Eine Wirkungsanalyse. Springer Gabler, S. 2-4.

Egbert, H., Greiff, M., Xhangolli, K. (2015). Pay What You Want (PWYW) pricing ex post consumption: a sales strategy for experience goods. Journal of Innovation Economics \& Management, 16(1), 49-264. doi: 10.3917/jie.016.0249

Gerpott, T. J. (2016). A review of the empirical literature on Pay-What-You-Want price setting. Management \& Marketing, 11(4), 566-596. doi: 10.1515/mmcks-2016-0017

Gläßner, A, (2017). Die Beschränkung des Vertriebs von Finanzprodukten. Nomos, 50.

Greiff, M., Egbert, H. (2018). A REVIEW OF THE EMPIRICAL EVIDENCE ON PWYW PRICING. Economic and Business Review for Central and South - Eastern Europe, 20(2), 169-193. doi: 10.15458/85451.64

Haws, K.L., Bearden, W.O. (2006), “Dynamic pricing and consumer fairness perceptions”,

Hinz, O., Creusen, U. (2009). Interaktive Preismechanismen - Die Preisverhandlung als Begegnung mit dem Kunden. Marketing Review St. Gallen, 6 (2009), 37-41. doi: 10.1007/s11621-009-0089-3

Hofmann, E. (2016). Zahl' doch einfach, was du willst!. Tectum Verlag. 33-48, 179.

Hummel R. (2020). Krisenmanagement in Medienunternehmen. In: Krone J., Pellegrini T. (eds) Handbuch Medienökonomie. Springer VS, 705-720.

Intention: Experiences of Generation Y Apparel Student Consumers within the Vaal Triangle. International Journal of Research in Business Studies and Management, 2, 24-31.

Journal of Consumer Research, 33 (3), 304-311. doi: 10.1086/508435

Kalka, R., Krämer, A. (2020). Preiskommunikation. Springer Gabler. 12, 78-82.

Kim, J., Kaufmann, K., Stegemann, M. (2013). The impact of buyer-seller relationships and reference prices on the effectiveness of the pay what you want pricing mechanism. Marketing Letters, 25, 409-423. doi: 10.1007/s11002-013-92612

Kochhan, C., Elsässer, A., Hachenberg, M. (2020). Marketing- und Kommunikationstrends. Springer Gabler, 1.

Krämer, F., Schmidt, K.M., Spann, M., Stich L. (2017). Delegating pricing power to customers: Pay What You Want or Name Your Own Price? Journal of Economic Behavior \& Organization, 136, 125-140. doi: 10.1016/j.jebo.2017.01.019

Kukla- Gryz, A., Zagorska, K. (2017). THE STRENGTH OF THE ANCHORING EFFECT ON PAY WHAT YOU WANT PAYMENTS: EVIDENCE FROM A VIGNETTE EXPERIMENT. Working Papers 2017-14, University of Warsaw.

Kunter, M., (2015). Exploring the Pay-What-You-Want payment motivation. Journal of Business Research, 68, $2347-2357$.

Marett, K., Pearson, R., Moore, R. S. (2012). Pay What You Want: An Exploratory Study of Social Exchange and BuyerDetermined Prices of iProducts. Communications of the Association for Information Systems, 30, article 10. doi: 10.17705/1CAIS.03010

Maziriri, E.T., Madinga, N. W. (2015). The Effect of Buyer's Remorse on Consumer's Repeat-Purchase

Menthe, T., Sieg, M. (2018) Kauf und Entscheidungsfindung. In: Kundennutzen - Schlüssel zum Verkaufserfolg. Springer Gabler, 1-21.

Mündges S., Lobigs F. (2020) Tages-, Wochen- und Gratiszeitungen und Anzeigenblätter. In: Krone J., Pellegrini T. (eds) Handbuch Medienökonomie. Springer VS, 779-799.

Narwal, P., Nayak, J. K. (2019). How consumers respond to social norms: an evidence from pay-what-you-want (PWYW) pricing. Journal of Consumer Marketing. doi:10.1108/jcm-05-2018-2677 
Niebert, K., Gropengießer, H. (2013). Leitfadengestützte Interviews. In: Krüger D., Parchmann I., Schecker H. (eds) Methoden in der naturwissenschaftsdidaktischen Forschung. Springer Spektrum, 121-132.

Pütter, M. (2019). Social Impact: Der Einfluss sozialer Medien auf unsere Kaufabsichten. Journal für korporative Kommunikation, 1(2019), 8-21.

Raju, J, Zhang, Z. (2010). Smart Pricing. Pearson, 22.

Riener, G., Traxler, C. (2012). Norms, moods, and free lunch: Longitudinal evidence on payments from a pay-what-you-want restaurant. Journal of Socio-Economics, 41, 476-483. doi:10.1016/j.socec.2011.07.003

Roy, R., Rabbanee, F. K., Sharma, P. (2016). Antecedents, outcomes, and mediating role of internal reference prices in paywhat-you-want (PWYW) pricing. Marketing Intelligence \& Planning, 34(1), 119.

Samahita, M. (2019). Pay-What-You-Want in Competition. The B.E. Journal of Theoretical Economics, 20(1), S. 1-16. Doi: 10.1515/bejte-2018-0063

Sander, M. (2019). Marketing Management. Utb. 506-507.

Schmidt, K.M., Spann, M., Zeithammer, R. (2015). Pay What You Want as a Marketing Strategy. Management Science, 61(6), 1217-1236. doi: 10.1287/mnsc.2014.1946

Schons, L.M., Rese, M., Wieseke, J., Rasmussen, W., Weber, D., Strotman, W.C. (2014). There is nothing permanent except change - analyzing individual price dynamics in "pay-what-you-want" situations. Marketing Letters, 25, 25-36. doi: $10.1007 / \mathrm{s} 11002-013-9237-2$

Stürmer, R., Schmidt, J. (2014). Erfolgreiches Marketing durch Emotionsforschung: Messung, Analyse, Best Practice. Haufe, 105-112.

Weisstein, F.L., Choi, P., Andersen, P. (2019). The role of external reference price in pay-what-you-want pricing: An empirical investigation across product types. Journal of Retailing and Consumer Services, 50, 170-178. doi: 10.1016/j.jretconser.2019.05.017

Witt, H. (2001). Forschungsstrategien bei quantitativer und qualitativer Sozialforschung [36 Absätze]. Forum qualitative Sozialforschung / Forum: Qualitative Social Research [On-line Journal], 2(1).

Zurstiege, G. (2020). Digitale Transformation der Werbung. In Moser, K., Eder, F., Keller, M., Grenzenlose Werbung: Zwischen Konsum und Audiovision. Degruyter, 289. 